\title{
The many roles of microRNAs in brain tumor biology
}

\author{
*Jay D. Turner, M.D., Ph.D., ${ }^{1}$ *Richard Williamson, M.D., ${ }^{*}$ Kaith K. Almefty, M.D., 1 \\ Peter Nakaji, M.D., ${ }^{1}$ Randall Porter, M.D., ${ }^{1}$ Victor Tse, M.D., Ph.D., ${ }^{2}$ \\ and M. Yashar S. Kalani, M.D., Ph.D. ${ }^{1}$ \\ 'Division of Neurosurgery, Barrow Neurological Institute, Phoenix, Arizona; \\ and ${ }^{2}$ Department of Neurosurgery, The Permanente Medical Group, Redwood City, California
}

\begin{abstract}
MicroRNAs (miRNAs) are now recognized as the primary RNAs involved in the purposeful silencing of the cell's own message. In addition to the established role of miRNAs as developmental regulators of normal cellular function, they have recently been shown to be important players in pathological states such as cancer. The authors review the literature on the role of miRNAs in the formation and propagation of gliomas and medulloblastomas, highlighting the potential of these molecules and their inhibitors as therapeutics. (DOI: 10.3171/2009.10.FOCUSO9207)
\end{abstract}

KEY WORDS • microRNA • glioma • medulloblastoma • cancer stem cell

$\mathrm{M}$ ICRORNAs are now recognized as the primary endogenous small RNAs, about 21 nucleotides in length (21-23 nucleotides), involved in the purposeful silencing of the cell's own message in a variety of ways, including translational repression, mRNA cleavage, and deadenylation. They were first described in Caenorhabditis elegans with the discovery that lin-4 coded for an RNA transcript capable of modulating the protein expression of $l i n-14 .{ }^{42}$ After their initial discovery in 1993, miRNA research proliferated and a variety of screening efforts have led to the discovery of hundreds of miRNAs. MicoRNAs are now considered fundamental to normal cellular function in eukaryotes, and the alteration of miRNA expression and activity has been implicated in a variety of pathological processes.

\section{Biogenesis}

MicroRNAs are stem-loop structures encoded by a cell's own genome. They interact with complementary mRNA leading to the disruption of target protein expression. MicroRNAs are generated by a multistep process (Fig. 1). Each miRNA can be transcribed separately from an individual transcriptional unit, or each transcriptional unit can encode a cluster of distinct miRNAs; miRNAs

Abbreviations used in this paper: miRNA = microRNA; npBAF = neural-progenitor-specific BAF; REST = repressor-element1-silencing transcription factor; RISC = RNA-induced silencing complex.

"These authors contributed equally to this work. can also be processed directly from other RNA species, such as introns by Dicer. ${ }^{2}$ The primary miRNA transcript (often abbreviated pri-miRNA) is typically transcribed from the genome by RNA polymerase II and is subsequently capped and polyadenylated..$^{40}$ The primary miRNA transcript folds into a stem-loop structure, which is essential for the maturation process. In animals, the primary miRNA transcript is then cleaved in the nucleus by Drosha, an RNase III endonuclease, in association with the double-stranded RNA-binding domain protein DGCR8/Pasha in a protein complex referred to as the microprocessor complex. ${ }^{17}$ Drosha cleaves both strands of the stem at sites near the base of the primary stem-loop, ${ }^{43}$ generating an intermediate known as the miRNA precursor (sometimes abbreviated premiRNA or pre-miRNA). The miRNA precursor is then exported out of the nucleus by Exportin-5 into the cytosol where the RNase III domain-containing nuclease, Dicer, cleaves the terminal loop to generate the $\sim 22$ nucleotide mature miRNA. Dicer functions with the double-stranded RNA-binding domain proteins TRBP and PACT. ${ }^{46}$ Drosha and Dicer cleave with great precision, generating very exact ends, and it is this feature that is likely responsible for the high specificity of miRNA with their target mRNA. ${ }^{8}$

\section{Posttranscriptional Gene Silencing}

Immediately after formation of the mature miRNA, the duplex is unwound and loaded onto the RNA-induced silencing complex, which ultimately carries out the silencing of target mRNA. The RISC is a trimeric complex composed of Dicer, TRBP, and a protein of the 


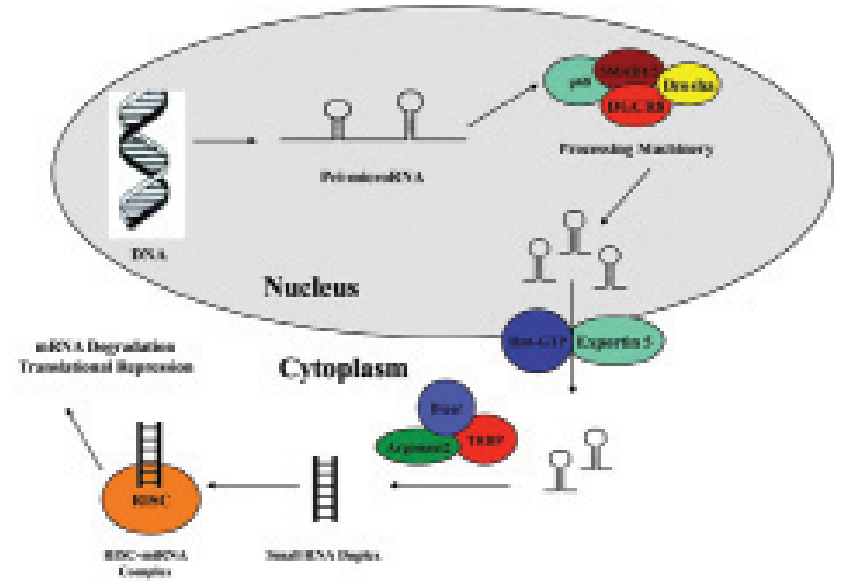

Fig. 1. Long primary miRNAs (pri-microRNAs) are processed in the nucleus into stem-loop precursors by the RNase III endonuclease Drosha and Pasha. The products of the enzymatic reaction are transported into the cytoplasm by exportin 5 and Ran-GTP, and these precursors are further processed into small RNA duplexes of approximately 22 nucleotides by the Dicer RNase III enzyme and Loqacious (Loqs). The microRNA duplex is then loaded onto the RNA-induced silencing complex (RISC). The microRNA guides the RISC to the target mRNA for translational regulation.

Argonaute superfamily (Ago2 in humans)..$^{30}$ It identifies target mRNA based on complementarity with the associated single-stranded miRNA and results in either mRNA cleavage or translational repression. ${ }^{2}$ An estimated onethird of all mRNAs are thought to be susceptible to posttranscriptional gene silencing by miRNAs ${ }^{66}$

\section{MicroRNA and Neuronal Development}

One of the most defining moments in the development of the nervous system is when neuroprogenitors lose multipotency at mitotic exit and begin to develop their terminal cell fate. In the case of neurons, it means they commit to their final topographical position and established stable connections that will persist for the lifetime of the organism. This transition is in large part accompanied by a switch in chromatin-remodeling/regulatory complexes such as in the exchange of the BAF53a and BAF45a subunits within Swi/Snf-like npBAF complexes. The subunits of the npBAF complex are essential for neural-progenitor proliferation. The exchange of the BAF53a and BAF45a in the neuron-specific BAF complex promotes postmitotic neural development and dendritic morphogenesis (Fig. 2). MicroRNA (miR-9* and miR-124) has been implicated in this process by regulating the chromatin architecture and dynamics. ${ }^{72}$ Interestingly, miR-9* and miR-124 are repressed by the REST, which mediates cell type- and developmental stage-specific gene repression, gene activation, and long-term gene silencing for protein-coding genes resulting in postmitotic neurons. The expression and function of REST are tightly regulated by context-specific transcriptional and posttranscriptional mechanisms including bidirectional feedback loops with various miRNAs. It is therefore not surprising that deregulation of REST and miRNAs are both implicated in the pathogenesis of various brain tumors.

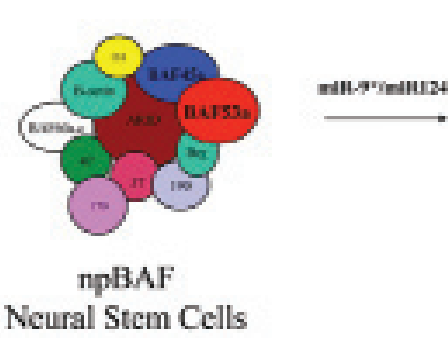

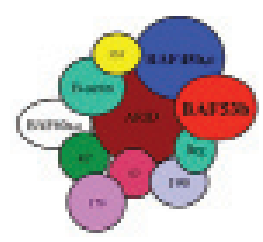

nBAF

Post-mitotic neurons
Fıg. 2. The subunits of the npBAF complex are essential for neuralprogenitor proliferation. The exchange of the BAF53a and BAF45a in the nBAF (neuron-specific BAF) complex promotes postmitotic neural development and dendritic morphogenesis.

\section{MicroRNA Function and Cancer}

Following the discovery of miRNAs and other small RNAs, a wealth of data were rapidly generated, which revealed a novel mechanism for the modulation of gene expression. As gene-finding computational models have evolved from simple homology-based searches to more complex multifactorial models, the number of identified miRNAs has continued to grow. ${ }^{47}$ Over recent years, there has been a significant push to better understand how they function in both normal and pathological states.

Though miRNAs have been demonstrated to modulate genes involved in a variety of cellular processes, a significant proportion of miRNAs regulate genes associated with cellular fate. It is now well accepted that miRNAs are fundamental to the regulation of proliferation, differentiation, and apoptosis during normal development. It has been shown that miRNAs have a predilection in targeting developmental genes. Genes involved in functions common to all cells, such as in maintenance and general activities, have very few miRNA target sites, and seem to be under selection to avoid targeting by miRNAs. ${ }^{61}$ Furthermore, alterations in the expression of miRNAs are seen in a variety of pathological processes, including cancer. Aberrant miRNA expression has been demonstrated in essentially every cancer type studied, including breast ${ }^{58,64,68,73}$ and ovarian carcinomas, ${ }^{48,74}$ pancreatic cancer, ${ }^{4,27}$ non-small cell lung cancer, ${ }^{41,56}$ leukemia, ${ }^{5-7}$ and brain tumors (Table 1). ${ }^{52,66}$ MicroRNA expression can be altered in cancer through a variety of mechanisms including chromosomal changes, epigenetic defects, mutations, and alterations in the machinery involved in miRNA biogenesis. ${ }^{66}$

Beyond mere biomarkers, the altered expression profiles of miRNA implicate them as key regulators of tumorigenesis. The miR-17-92 polycistron, located on chromosome 13q32-33, was the first example of miRNAs acting as mammalian oncogenes. ${ }^{35}$ This region of the chromosome is amplified in several types of cancer and can be activated by $c-M y c$, a well-established protooncogene overexpressed in different cancer types. ${ }^{51,66}$ The first individual miRNA assigned an oncogenic role was $m i R-155,{ }^{18}$ which when overexpressed in a transgenic mouse model, led to the development of B-cell leukemia and high-grade lymphoma. ${ }^{15}$

There is also evidence accumulating that miRNAs are involved in cell-cycle checkpoint regulation. Using a mutated version of dicer-1, Hatfield and colleagues ${ }^{33}$ dem- 


\section{Brain tumor biology and MicroRNAs}

TABLE 1: MicroRNAs implicated in glioma and medulloblastoma biology

\begin{tabular}{|c|c|c|}
\hline Tumor & miRNA & Cellular Role \\
\hline \multirow[t]{14}{*}{ GBM } & miR-7 & suppresses EGFR expression; independently inhibits Akt pathway \\
\hline & $\mathrm{miR}-10 \mathrm{~b}$ & may promote invasion; found to be increased in invasive high-grade gliomas \\
\hline & $\operatorname{miR}-15 b$ & results in cell cycle arrest \\
\hline & $\operatorname{miR}-21$ & anti-apoptosis; suppresses tumor supressors \\
\hline & miR-26a & targets PTEN; enhances Akt pathway \\
\hline & miR-124 & inhibits proliferation by inducing G0/G1 cell cylce arrest via CDK6 inhibition \\
\hline & miR-128 & expression decreases levels of Bmi-1 \\
\hline & $\operatorname{miR}-137$ & inhibits proliferation by inducing G0/G1 cell cylce arrest via CDK6 inhibition \\
\hline & miR-181a & tumor supressor \\
\hline & miR-181b & tumor supressor \\
\hline & miR-221 & unknown; found to be increased in invasive high-grade gliomas \\
\hline & $\operatorname{miR}-425$ & upregulated in non-cancer stem cells; promotes differentiation \\
\hline & $\operatorname{miR}-451$ & upregulated in non-cancer stem cells; promotes differentiation \\
\hline & $\operatorname{miR}-486$ & upregulated in non-cancer stem cells; promotes differentiation \\
\hline \multirow[t]{13}{*}{$\mathrm{MB}$} & miR-let7g & upregulated in anaplastic MB; differentially expressed in desmoplastic MB \\
\hline & $\operatorname{miR}-9$ & regulates proliferation, apoptosis \\
\hline & miR-19a & over-expressed in hedgehog-dependent MB; upregulated in anaplastic MB \\
\hline & miR-20 & over-expressed in hedgehog-dependent MB \\
\hline & miR-92 & over-expressed in hedgehog-dependent MB \\
\hline & miR-106b & upregulated in anaplastic MB; differentially expressed in desmoplastic MB \\
\hline & miR-124 & regulates cell cycle via CKD6 \\
\hline & miR-125a & regulates proliferation, apoptosis \\
\hline & miR-125b & hedgehog dependent proliferation \\
\hline & miR-191 & upregulated in anaplastic MB \\
\hline & $\operatorname{miR}-199 b-5 p$ & expression correlates with decreased metastatic potential; associated with survival \\
\hline & $\operatorname{miR}-324-5 p$ & hedgehog dependent proliferation \\
\hline & $\mathrm{miR}-326$ & hedgehog dependent proliferation \\
\hline
\end{tabular}

onstrated that miRNAs modulated stem cell division in Drosophila by bypassing the G1/S checkpoint. This work suggested that miRNAs may make stem cells insensitive to environmental stimuli and that a similar mechanism may be implicated in tumorigenesis. ${ }^{16}$ More recently, specific miRNAs capable of regulating cellular checkpoints in cancer have been described, including miR-221, miR222, and miR-27a. . $^{45,49,67}$

In addition to their involvement in cancer formation, miRNAs have also been associated with tumor progression and metastatic potential. ${ }^{3}$ Although still not well characterized, specific miRNAs-such as miR-10b, miR21, miR-30a, miR-30e, miR-125b, miR-141, miR-200b, miR-200c, and miR-205-have been suggested to play an important role in tumor invasiveness and metastasis. ${ }^{1}$ Some of the targets of these miRNAs have recently been elucidated and include tumor suppressor genes such as tropomyosin 1 and other targets with metastatic potential such as PDCD4 and maspin. ${ }^{76}$

\section{MicroRNAs and Gliomas}

Gliomas are tumors arising from glial cells, the neuroepithelial support cells of the CNS. Gliomas are the most common primary tumor of the CNS comprising over $50 \%$ of primary brain tumors. ${ }^{62}$ Glioblastoma is the most common and deadliest glioma with approximately 10,000 new cases every year and a median survival of only 14 months even with the most current therapies. ${ }^{62}$ Gliomas, like tumors in other parts of the body, develop because of fundamental genetic alterations that cause the formation of a tumor stem cell population that divides without regard to normal physiological biochemical signaling. ${ }^{11,65}$ It is no surprise then that the same miRNAs that are involved in stem cell regulation and differentiation are also implicated in tumor stem cell biology of gliomas.

Microarray studies of glioma tissue have implicated a number of miRNAs involved in glioma formation and propagation. In their quantitative reverse transcriptase polymerase chain reaction analysis of high-grade astrocytomas in humans (glioblastomas and anaplastic astrocytomas), Silber et al. ${ }^{59}$ found 35 different miRNAs that were significantly deregulated compared with control brain tissue. Those miRNAs that have been shown to play a role in human glioma include miR-7, $-10 b,-15 b$, $-21,-26 a,-124,-128,-137,-181 a,-181 b,-221,-451$, and others. The majority of miRNAs are underexpressed in proliferating glioma cells with the important exception of miR-10b, -21, and -221.

MicroRNAs are key regulators of tumor suppressor genes. The overexpression of miR-21, a recently described 
antiapoptotic factor, appears to be vitally important in not only glioma but also cancer arising from other parts of the body. ${ }^{9}$ Chen and coworkers ${ }^{10}$ used bioinformatics analysis to screen and identify various genes with miR21 binding sites. Using the glioblastoma cell line T98G, they confirmed that miR-21 binds and silences the tumor suppressor gene PDCD4. Corsten et al. ${ }^{14}$ transfected human glioma cells with anti-miR-21 oligonucleotides and simultaneously implanted neural precursor cells expressing a secretable variant of the cytotoxic agent TRAIL (S-TRAIL). They found a synergistic effect of knocking down miR-21 levels and adding the apoptotic agent $\mathrm{S}$ TRAIL evidenced by increased caspase activity and decreased cell viability in the human glioma cells in vitro. They then found complete eradication of tumor cells in a murine model transfected with anti-miR-21 and then exposed to S-TRAIL in vivo.

MicroRNAs regulate oncogenes implicated in brain tumor formation. The expression level of miR-128 is inversely correlated with expression level of transcription factor E2F3a, a protein that promotes cell entry into Sphase and implicated in cancer of the bladder and prostate. ${ }^{75}$ Godlewski and colleagues ${ }^{28}$ found that miR-128 levels were downregulated in glioma cells compared with normal brain tissue. They reported that increasing miR128 expression leds to a decrease in the expression of the oncogene Bmi-1. Overexpression of miR-128 in glioma neurosphere cultures specifically blocks glioma self-renewal consistent with Bmi-l downregulation.

Interestingly, other than serving as key regulators of oncogenes and tumor suppressors, microRNAs may also dictate the invasiveness and aggressiveness of tumors. Conti et al. ${ }^{13}$ found both miR-21 and miR-221 upregulated in glioma samples; however, they noted that whereas miR-21 was elevated in all gliomas, high levels of miR221 were only found in high-grade gliomas. MicroRNA$10 \mathrm{~b}$ has similarly been associated with high-grade tumors. Overexpression of miR-10b may promote glioma invasion via the RhoC and urokinase plasminogen activator receptor (uPAR), which have been implicated in other cancers as prometastatic and proinvasive factors. ${ }^{55}$ Huse and colleagues ${ }^{37}$ studied the overexpression of miR-26a in a subset of high-grade glioma, most often associated with monoallelic loss of phosphatase and tensin homolog (PTEN). Studying 3 human glioblastoma samples, they found that miR-26a directly targets PTEN and enhances the Akt pathway. By transfecting miR-26a into a murine model, they were able to show that overexpression of miR-26a enhances gliomagenesis. Because miR-26a overexpression appears in only a subset of glioma with monoallelic loss of PTEN, they hypothesized that this overexpression functionally substitutes loss of heterozygosity at the PTEN locus.

MicroRNAs have also been shown to be important regulators of cellular proliferation/differentiation and the cell cycle. Silber and colleagues ${ }^{59}$ were the first to discover that miR-124 and miR-137 are downregulated in high-grade gliomas compared with normal controls. These microRNAs are also upregulated during adult neural stem cell differentiation. The upregulation of miR-124 and miR-137 in tumor stem cell populations promotes neuronal differentiation of the tumor stem cells and inhibits proliferation of the tumor cells by inducing G0/ G1 cell-cycle arrest. The mechanism of action is via the inhibition of CDK6 expression, a protein essential for cell-cycle progression. ${ }^{33}$ Kefas et al. ${ }^{39}$ studied miR-7, another miRNA that is downregulated in glioma. They found that miR-7 suppresses EGFR expression and independently inhibits the Akt pathway in glioblastoma. Transfection of glioblastoma with miR-7 decreased viability and invasiveness of primary glioblastoma cell lines and increased the apoptotic fraction of cells. Overexpression of miR-15b, another differentially expressed microRNA, results in cell-cycle arrest while suppression of miR-15b results in more cells in S-phase. ${ }^{70} \mathrm{Gal}$ and colleagues ${ }^{23}$ examined glioblastoma stem (CD133-positive) and nonstem (CD133-negative) cells and found that miR-451, -486, and -425 were significantly upregulated in CD133-negative cells compared with CD133-positive cells. Transfection of glioblastoma cells with these miRNAs inhibited neurosphere formation, and transfection with miR-451 resulted in neurosphere dispersion and inhibited glioblastoma growth. Gal and colleagues found that combining miR-451 transfection with Imatinib mesylate treatment had a cooperative effect in dispersal of glioblastoma neurospheres.

MicroRNAs have recently been shown to function as bona fide tumor suppressors. Shi et al. ${ }^{57}$ reported on downregulated miR-181a and miR-181b involved in glioma formation. Their study showed that these miRNAs functioned as tumor suppressors. Transfection of these miRNAs into glioblastoma cells inhibited proliferation in vitro, resulted in loss of anchorage-independent growth, induced apoptosis in glioma cell lines, and depressed the invasion of glioma cells in vitro.

\section{MicroRNAs and Medulloblastoma}

Medulloblastoma is the most common malignant brain tumor in children with an incidence of approximately 2 per 100,000. It appears to arise from stem cells and from granule neuron precursors in the external granule layer of the cerebellum ${ }^{26}$ or multipotent precursors in the ventricular zone of the cerebellum. ${ }^{44}$ About $70 \%$ of cases occur before the age of 16 years. Approximately one-third disseminate in the CSF and up to 5\% spread systemically. Medulloblastoma treatment most often involves a combination of surgery and radiation therapy. Chemotherapy is usually reserved for children younger than 3 years of age or for recurrent tumors. Five-year survival rates for medulloblastoma have been estimated to range from 35 to $75 \% .^{19}$

Evidence for a role of miRNA in medulloblastoma tumorigenesis has only very recently emerged. Pierson and associates ${ }^{54}$ were the first to report the involvement of miRNA in medulloblastoma by demonstrating that miR124 modulates cell-cycle regulation in medulloblastoma cells. They showed that miR-124 expression is significantly decreased in medulloblastoma and that augmentation of miR-124 levels can slow tumor cell growth by targeting CDK6.

Ferretti et al. ${ }^{21}$ proposed a role for miRNA in modulating hedgehog signaling, a pathway recently implicated 
in tumorigenesis for a subset of medulloblastoma. ${ }^{29,32,34}$ Specifically, they showed that miR-125b, miR-326, and miR-324-5p expression was decreased in medulloblastoma and that the altered expression of these miRNAs led to tumor cell proliferation through a hedgehog-dependent mechanism. Expanding on this work, Uziel et al. ${ }^{63}$ identified 3 miRNAs overexpressed in hedgehog-active medulloblastomas: miR-92, miR-19a, and miR-20. All 3 miRNAs were encoded by the miR-17/92 cluster, which has been associated with a variety of cancers. Northcutt and colleagues ${ }^{50}$ identified a high-level, focal amplification on chromosome 13q31.3, which mapped to the same miRNA cluster. The expression of miR-17/92 was most elevated in medulloblastomas with activated hedgehog signaling and was also associated with elevated c-Myc and $\mathrm{n}$-Myc. These studies suggest that aberrant expression of miRNAs encoded by the miR-17/92 enhance the growth potential of medulloblastoma and that miRNA-mediated modulation of hedgehog signaling may be an important contributing factor to medulloblastoma pathogenesis.

Ferretti et al. ${ }^{22}$ used high-throughput screening to examine miRNA expression profiles in 34 patients with medulloblastoma. They identified 78 miRNAs with altered expression in medulloblastoma, compared with normal adult and fetal cerebellar cells. Several of the identified miRNAs have been implicated in other cancer types including glioblastoma..$^{12,25}$ The majority of these miRNAs were downregulated in medulloblastoma, supporting a role for miRNAs as tumor suppressors. Additionally, they found increased expression of miR-9 and miR-125a and that increased expression of these miRNAs was capable of decreasing proliferation, augmenting apoptosis, and ultimately promoting arrest of tumor growth. The proapoptotic effect was mediated by miR- 9 and miR125a targeting of the $\mathrm{t}-\mathrm{TrkC}$ receptor, which was found in this study to be upregulated in medulloblastoma cells. In this study, miRNA expression patterns were also examined in different tumor subsets. The authors found that miR-let7g, miR-19a, miR-106b, and miR-191 were significantly upregulated in anaplastic compared with desmoplastic medulloblastomas; miR-let7g and miR-106b were differentially expressed in desmoplastic compared with classic medulloblastomas; and miR19a was upregulated in anaplastic compared with classic medulloblastomas.

Changes in expression of Her2 (ErbB2) and c-Myc have been demonstrated to impact biological activity and clinical features of medulloblastoma. ${ }^{26,31,36}$ Ferretti et al. ${ }^{22}$ examined miRNA expression from medulloblastomas overexpressing either Her2 or c-Myc and identified an miRNA signature in each group of medulloblastomas. Expression of miR-10b, miR-135a, miR-135b, miR-125b, miR-153, and miR-199b was altered in Her2-overexpressing tumors, whereas c-Myc overexpressing medulloblastomas had expression changes in miR-181b, miR-128a, and miR-128b. Additionally, the amount of expression change of 2 miRNAs correlated with disease risk. Though miR-31 and miR-153 were downregulated in all medulloblastomas, the group found that the degree of change was directly proportional to disease severity.

It is well established that the Notch signaling pathway regulates the differentiation of granule neuron precursor cells and that Notch 2 expression is increased in about $15 \%$ of medulloblastomas. ${ }^{44,60}$ Expression of the transcriptional repressor HES1, a downstream effector protein of the Notch pathway, normally declines during the process of neuronal differentiation. Conversely, persistent activation of the Notch pathway and HES1 prevents the migration of granule neuron precursor cells out of the ventricular zone and inhibits neuronal differentiation. ${ }^{38}$ Based on its role in differentiation, it is not surprising that dysfunction of the Notch pathway has been associated with a subset of medulloblastoma with stem cell-like properties. ${ }^{20,69,71,77}$ Garzia et al. ${ }^{24}$ examined the role of miRNAs in the regulation of Notch/HES1 signaling in medulloblastoma. They found that miR-199b-5p targeted HES1 and that miR-199b-5p-mediated downregulation of HES1 attenuated cellular proliferation in medulloblastoma cell lines. In medulloblastoma patients, increased expression of miR-199b-5p appeared to decrease metastatic potential and was associated with increased survival.

\section{Conclusions}

Although the investigation of miRNAs in brain tumors is still in its infancy, there is strong evidence mounting that miRNAs are integrally involved in brain tumor development and progression. It is becoming clear that miRNAs are essential regulators of many of the key pathways implicated in tumor pathogenesis. While adding another layer of complexity, the discovery of the role miRNAs in brain tumors has also revealed a new category of therapeutic targets. As miRNA research continues to evolve, novel therapeutic targets for the treatment of brain tumors will continue to emerge.

\section{Disclosure}

The authors report no conflict of interest concerning the materials or methods used in this study or the findings specified in this paper.

\section{References}

1. Baffa R, Fassan M, Volinia S, O’Hara B, Liu CG, Palazzo JP, et al: MicroRNA expression profiling of human metastatic cancers identifies cancer gene targets. J Pathol 219:214-221 2009

2. Bartel DP: MicroRNAs: genomics, biogenesis, mechanism, and function. Cell 116:281-297, 2004

3. Bartels CL, Tsongalis GJ: MicroRNAs: novel biomarkers for human cancer. Clin Chem 55:623-631, 2009

4. Bloomston M, Frankel WL, Petrocca F, Volinia S, Alder H, Hagan JP, et al: MicroRNA expression patterns to differentiate pancreatic adenocarcinoma from normal pancreas and chronic pancreatitis. JAMA 297:1901-1908, 2007

5. Calin GA, Dumitru CD, Shimizu M, Bichi R, Zupo S, Noch E, et al: Frequent deletions and down-regulation of micro- RNA genes miR15 and miR16 at 13q14 in chronic lymphocytic leukemia. Proc Natl Acad Sci U S A 99:15524-15529, 2002

6. Calin GA, Ferracin M, Cimmino A, Di Leva G, Shimizu M, Wojcik SE, et al: A MicroRNA signature associated with prognosis and progression in chronic lymphocytic leukemia. N Engl J Med 353:1793-1801, 2005

7. Calin GA, Liu CG, Sevignani C, Ferracin M, Felli N, Dumitru $\mathrm{CD}$, et al: MicroRNA profiling reveals distinct signatures in $\mathrm{B}$ 
cell chronic lymphocytic leukemias. Proc Natl Acad Sci U S A 101:11755-11760, 2004

8. Carthew RW, Sontheimer EJ: Origins and Mechanisms of miRNAs and siRNAs. Cell 136:642-655, 2009

9. Chan JA, Krichevsky AM, Kosik KS: MicroRNA-21 is an antiapoptotic factor in human glioblastoma cells. Cancer Res 65:6029-6033, 2005

10. Chen Y, Liu W, Chao T, Zhang Y, Yan X, Gong Y, et al: MicroRNA-21 down-regulates the expression of tumor suppressor PDCD4 in human glioblastoma cell T98G. Cancer Lett 272:197-205, 2008

11. Cheshier SH, Kalani MY, Lim M, Ailles L, Huhn SL, Weissman IL: A neurosurgeon's guide to stem cells, cancer stem cells, and brain tumor stem cells. Neurosurgery 65:237-250, 2009

12. Ciafrè SA, Galardi S, Mangiola A, Ferracin M, Liu CG, Sabatino $\mathrm{G}$, et al: Extensive modulation of a set of microRNAs in primary glioblastoma. Biochem Biophys Res Commun 334:1351-1358, 2005

13. Conti A, Aguennouz M, La Torre D, Tomasello C, Cardali S, Angileri FF, et al: miR-21 and 221 upregulation and miR-181b downregulation in human grade II-IV astrocytic tumors. J Neurooncol 93:325-332, 2009

14. Corsten MF, Miranda R, Kasmieh R, Krichevsky AM, Weissleder R, Shah K: MicroRNA-21 knockdown disrupts glioma growth in vivo and displays synergistic cytotoxicity with neural precursor cell delivered S-TRAIL in human gliomas. Cancer Res 67:8994-9000, 2007

15. Costinean S, Zanesi N, Pekarsky Y, Tili E, Volinia S, Heerema N, et al: Pre-B cell proliferation and lymphoblastic leukemia/ high-grade lymphoma in $\mathrm{E}(\mathrm{mu})-\mathrm{miR} 155$ transgenic mice. Proc Natl Acad Sci U S A 103:7024-7029, 2006

16. Croce CM, Calin GA: miRNAs, cancer, and stem cell division. Cell 122:6-7, 2005

17. Denli AM, Tops BB, Plasterk RH, Ketting RF, Hannon GJ: Processing of primary microRNAs by the Microprocessor complex. Nature 432:231-235, 2004

18. Eis PS, Tam W, Sun L, Chadburn A, Li Z, Gomez MF, et al: Accumulation of miR-155 and BIC RNA in human B cell lymphomas. Proc Natl Acad Sci U S A 102:3627-3632, 2005

19. Evans AE, Jenkin RD, Sposto R, Ortega JA, Wilson CB, Wara W, et al: The treatment of medulloblastoma. Results of a prospective randomized trial of radiation therapy with and without CCNU, vincristine, and prednisone. J Neurosurg 72:572-582, 1990

20. Fan X, Matsui W, Khaki L, Stearns D, Chun J, Li YM, et al: Notch pathway inhibition depletes stem-like cells and blocks engraftment in embryonal brain tumors. Cancer Res 66:7445-7452, 2006

21. Ferretti E, De Smaele E, Miele E, Laneve P, Po A, Pelloni M, et al: Concerted microRNA control of Hedgehog signalling in cerebellar neuronal progenitor and tumour cells. EMBO J 27:2616-2627, 2008

22. Ferretti E, De Smaele E, Po A, Di Marcotullio L, Tosi E, Espinola MS, et al: MicroRNA profiling in human medulloblastoma. Int J Cancer 124:568-577, 2009

23. Gal H, Pandi G, Kanner AA, Ram Z, Lithwick-Yanai G, Amariglio N, et al: MIR-451 and Imatinib mesylate inhibit tumor growth of Glioblastoma stem cells. Biochem Biophys Res Commun 376:86-90, 2008

24. Garzia L, Andolfo I, Cusanelli E, Marino N, Petrosino G, De Martino D, et al: MicroRNA-199b-5p impairs cancer stem cells through negative regulation of HES1 in medulloblastoma. PLoS One 4:e4998, 2009

25. Gaur A, Jewell DA, Liang Y, Ridzon D, Moore JH, Chen C, et al: Characterization of microRNA expression levels and their biological correlates in human cancer cell lines. Cancer Res 67:2456-2468, 2007

26. Gilbertson RJ, Perry RH, Kelly PJ, Pearson AD, Lunec J:
Prognostic significance of HER2 and HER4 coexpression in childhood medulloblastoma. Cancer Res 57:3272-3280, 1997

27. Gironella M, Seux M, Xie MJ, Cano C, Tomasini R, Gommeaux J, et al: Tumor protein 53 -induced nuclear protein 1 expression is repressed by miR-155, and its restoration inhibits pancreatic tumor development. Proc Natl Acad Sci US A 104: 16170-16175, 2007

28. Godlewski J, Nowicki MO, Bronisz A, Williams S, Otsuki A, Nuovo G, et al: Targeting of the Bmi-1 oncogene/stem cell renewal factor by microRNA-128 inhibits glioma proliferation and self-renewal. Cancer Res 68:9125-9130, 2008

29. Goodrich LV, Milenković L, Higgins KM, Scott MP: Altered neural cell fates and medulloblastoma in mouse patched mutants. Science 277:1109-1113, 1997

30. Gregory RI, Chendrimada TP, Cooch N, Shiekhattar R: Human RISC couples microRNA biogenesis and posttranscriptional gene silencing. Cell 123:631-640, 2005

31. Grotzer MA, Hogarty MD, Janss AJ, Liu X, Zhao H, Eggert A, et al: MYC messenger RNA expression predicts survival outcome in childhood primitive neuroectodermal tumor/ medulloblastoma. Clin Cancer Res 7:2425-2433, 2001

32. Hallahan AR, Pritchard JI, Hansen S, Benson M, Stoeck J, Hatton BA, et al: The SmoA1 mouse model reveals that notch signaling is critical for the growth and survival of sonic hedgehog-induced medulloblastomas. Cancer Res 64:77947800,2004

33. Hatfield SD, Shcherbata HR, Fischer KA, Nakahara K, Carthew RW, Ruohola-Baker H: Stem cell division is regulated by the microRNA pathway. Nature 435:974-978, 2005

34. Hatten ME: Expansion of CNS precursor pools: a new role for Sonic Hedgehog. Neuron 22:2-3, 1999

35. He L, Thomson JM, Hemann MT, Hernando-Monge E, Mu $\mathrm{D}$, Goodson S, et al: A microRNA polycistron as a potential human oncogene. Nature 435:828-833, 2005

36. Herms J, Neidt I, Lüscher B, Sommer A, Schürmann P, Schröder T, et al: C-MYC expression in medulloblastoma and its prognostic value. Int J Cancer 89:395-402, 2000

37. Huse JT, Brennan C, Hambardzumyan D, Wee B, Pena J, Rouhanifard SH, et al: The PTEN-regulating microRNA miR-26a is amplified in high-grade glioma and facilitates gliomagenesis in vivo. Genes Dev 23:1327-1337, 2009

38. Ishibashi M, Moriyoshi K, Sasai Y, Shiota K, Nakanishi S, Kageyama R: Persistent expression of helix-loop-helix factor HES-1 prevents mammalian neural differentiation in the central nervous system. EMBO J 13:1799-1805, 1994

39. Kefas B, Godlewski J, Comeau L, Li Y, Abounader R, Hawkinson $\mathrm{M}$, et al: microRNA-7 inhibits the epidermal growth factor receptor and the Akt pathway and is down-regulated in glioblastoma. Cancer Res 68:3566-3572, 2008

40. Kim VN: MicroRNA biogenesis: coordinated cropping and dicing. Nat Rev Mol Cell Biol 6:376-385, 2005

41. Kumar MS, Erkeland SJ, Pester RE, Chen CY, Ebert MS, Sharp PA, et al: Suppression of non-small cell lung tumor development by the let-7 microRNA family. Proc Natl Acad Sci U S A 105:3903-3908, 2008

42. Lee RC, Feinbaum RL, Ambros V: The C. elegans heterochronic gene lin-4 encodes small RNAs with antisense complementarity to lin-14. Cell 75:843-854, 1993

43. Lee Y, Ahn C, Han J, Choi H, Kim J, Yim J, et al: The nuclear RNase III Drosha initiates microRNA processing. Nature 425:415-419, 2003

44. Marino S: Medulloblastoma: developmental mechanisms out of control. Trends Mol Med 11:17-22, 2005

45. Medina R, Zaidi SK, Liu CG, Stein JL, van Wijnen AJ, Croce CM, et al: MicroRNAs 221 and 222 bypass quiescence and compromise cell survival. Cancer Res 68:2773-2780, 2008

46. Meister G, Tuschl T: Mechanisms of gene silencing by doublestranded RNA. Nature 431:343-349, 2004 
47. Mendes ND, Freitas AT, Sagot MF: Current tools for the identification of miRNA genes and their targets. Nucleic Acids Res 37:2419-2433, 2009

48. Merritt WM, Lin YG, Han LY, Kamat AA, Spannuth WA, Schmandt R, et al: Dicer, Drosha, and outcomes in patients with ovarian cancer. N Engl J Med 359:2641-2650, 2008

49. Mertens-Talcott SU, Chintharlapalli S, Li X, Safe S: The oncogenic microRNA-27a targets genes that regulate specificity protein transcription factors and the G2-M checkpoint in MDA-MB-231 breast cancer cells. Cancer Res 67:1100111011,2007

50. Northcott PA, Fernandez-L A, Hagan JP, Ellison DW, Grajkowska W, Gillespie Y, et al: The miR-17/92 polycistron is up-regulated in sonic hedgehog-driven medulloblastomas and induced by $\mathrm{N}$-myc in sonic hedgehog-treated cerebellar neural precursors. Cancer Res 69:3249-3255, 2009

51. O'Donnell KA, Wentzel EA, Zeller KI, Dang CV, Mendell JT: c-Myc-regulated microRNAs modulate E2F1 expression. Nature 435:839-843, 2005

52. Pang JC, Kwok WK, Chen Z, Ng HK: Oncogenic role of microRNAs in brain tumors. Acta Neuropathol 117:599-611, 2009

53. Papagiannakopoulos T, Kosik KS: MicroRNAs: regulators of oncogenesis and stemness. BMC Med 6:15, 2008

54. Pierson J, Hostager B, Fan R, Vibhakar R: Regulation of cyclin dependent kinase 6 by microRNA 124 in medulloblastoma. J Neurooncol 90:1-7, 2008

55. Sasayama T, Nishihara M, Kondoh T, Hosoda K, Kohmura E: MicroRNA-10b is overexpressed in malignant glioma and associated with tumor invasive factors, uPAR and RhoC. Int J Cancer 125:1407-1413, 2009

56. Seike M, Goto A, Okano T, Bowman ED, Schetter AJ, Horikawa I, et al: MiR-21 is an EGFR-regulated anti-apoptotic factor in lung cancer in never-smokers. Proc Natl Acad Sci U S A 106:12085-12090, 2009

57. Shi L, Cheng Z, Zhang J, Li R, Zhao P, Fu Z, et al: hsa-mir181a and hsa-mir-181b function as tumor suppressors in human glioma cells. Brain Res 1236:185-193, 2008

58. Shimono Y,Zabala M, Cho RW, Lobo N, Dalerba P, Qian D, et al: Downregulation of miRNA-200c links breast cancer stem cells with normal stem cells. Cell 138:592-603, 2009

59. Silber J, Lim DA, Petritsch C, Persson AI, Maunakea AK, Yu M, et al: miR-124 and miR-137 inhibit proliferation of glioblastoma multiforme cells and induce differentiation of brain tumor stem cells. BMC Med 6:14, 2008

60. Solecki DJ, Liu XL, Tomoda T, Fang Y, Hatten ME: Activated Notch2 signaling inhibits differentiation of cerebellar granule neuron precursors by maintaining proliferation. Neuron 31:557-568, 2001

61. Stark A, Brennecke J, Bushati N, Russell RB, Cohen SM: Animal MicroRNAs confer robustness to gene expression and have a significant impact on 3'UTR evolution. Cell 123:11331146,2005

62. Stupp R, Mason WP, van den Bent MJ, Weller M, Fisher B, Taphoorn MJ, et al : Radiotherapy plus concomitant and adjuvant temozolomide for glioblastoma. N Engl J Med 352:987996, 2005

63. Uziel T, Karginov FV, Xie S, Parker JS, Wang YD, Gajjar A, et al: The miR-17 92 cluster collaborates with the Sonic Hedge- hog pathway in medulloblastoma. Proc Natl Acad Sci U S A 106:2812-2817, 2009

64. Valastyan S, Reinhardt F, Benaich N, Calogrias D, Szász AM, Wang ZC, et al: A pleiotropically acting microRNA, miR-31, inhibits breast cancer metastasis. Cell 137:1032-1046, 2009

65. Veeravagu A, Bababeygy SR, Kalani MY, Hou LC, Tse V: The cancer stem cell-vascular niche complex in brain tumor formation. Stem Cells Dev 17:859-867, 2008

66. Visone R, Croce CM: MiRNAs and cancer. Am J Pathol 174:1131-1138, 2009

67. Visone R, Russo L, Pallante P, De Martino I, Ferraro A, Leone V, et al: MicroRNAs (miR)-221 and miR-222, both overexpressed in human thyroid papillary carcinomas, regulate p27Kip1 protein levels and cell cycle. Endocr Relat Cancer 14:791-798, 2007

68. Volinia S, Calin GA, Liu CG, Ambs S, Cimmino A, Petrocca F, et al: A microRNA expression signature of human solid tumors defines cancer gene targets. Proc Natl Acad Sci U S A 103:2257-2261, 2006

69. Wang Q, Li H, Liu N, Chen XY, Wu ML, Zhang KL, et al: Correlative analyses of notch signaling with resveratrol-induced differentiation and apoptosis of human medulloblastoma cells. Neurosci Lett 438:168-173, 2008

70. Xia H, Qi Y, Ng SS, Chen X, Chen S, Fang M, et al: MicroRNA-15b regulates cell cycle progression by targeting cyclins in glioma cells. Biochem Biophys Res Commun 380:205210, 2009

71. Yokota N, Mainprize TG, Taylor MD, Kohata T, Loreto M, Ueda S, et al: Identification of differentially expressed and developmentally regulated genes in medulloblastoma using suppression subtraction hybridization. Oncogene 23:3444-3453, 2004

72. Yoo AS, Staahl BT, Chen L, Crabtree GR: MicroRNA-mediated switching of chromatin-remodelling complexes in neural development. Nature 460:642-646, 2009

73. Zhang L, Huang J, Yang N, Greshock J, Megraw MS, Giannakakis A, et al: microRNAs exhibit high frequency genomic alterations in human cancer. Proc Natl Acad Sci U S A 103:9136-9141, 2006

74. Zhang L, Volinia S, Bonome T, Calin GA, Greshock J, Yang $\mathrm{N}$, et al: Genomic and epigenetic alterations deregulate microRNA expression in human epithelial ovarian cancer. Proc Natl Acad Sci U S A 105:7004-7009, 2008

75. Zhang Y, Chao T, Li R, Liu W, Chen Y, Yan X, et al: MicroRNA-128 inhibits glioma cells proliferation by targeting transcription factor E2F3a. J Mol Med 87:43-51, 2009

76. Zhu S, Wu H, Wu F, Nie D, Sheng S, Mo YY: MicroRNA-21 targets tumor suppressor genes in invasion and metastasis. Cell Res 18:350-359, 2008

77. Zweidler-McKay PA: Notch signaling in pediatric malignancies. Curr Oncol Rep 10:459-468, 2008

Manuscript submitted September 4, 2009.

Accepted October 21, 2009.

Address correspondence to: M. Yashar S. Kalani, M.D., Ph.D., Department of Neurosurgery, Kaiser Permanente Medical Center, 1150 Veterans Boulevard, Redwood City, California 94063. email: Yashar.Kalani@bnaneuro.net. 